\title{
Effects of curvature in hybrid poplar on acoustic velocity at the tree level
}

\author{
Normand Paradis ${ }^{1}$ and Glen E Murphy ${ }^{2^{*}}$
}

\begin{abstract}
Background and Methods: Measurements of stress wave velocity were performed with the Fibre-gen Director ST300 on 146 hybrid poplar (Populus sp.) plantation trees from GreenWood Resources Inc. located near the city of Boardman, Oregon USA. A laser scanner (Faro Focus 3D) was used to measure the curvature of the trees. Combinations of two software tools (Treemetrics Autostem and Sweep Extractor) were used to calculate the curvature for two log lengths ( 3 and $6 \mathrm{~m}$ ) from a height of $10 \mathrm{~cm}$ above the ground. The propagation velocities of the stress waves were measured twice; first at breast height on the convex side of the stem and then at 90 degrees clockwise around the stem from the first measurement.

Results and Conclusions: Analysis of the data showed that there was no significant difference $(p=0.24)$ between propagation velocities when the probes were located on either the convex side or at 90 degrees to the convex side. However, the propagation velocity was significantly greater on trees with higher curvature, suggesting that the velocities measured with the ST300 can take into account the presence of reaction wood (tension wood) in the tree.
\end{abstract}

Keywords: Wood properties; Stem curvature; Laser scanning; Sweep assessment; Curvature

\section{Background}

The development of tools for non-destructive evaluation of mechanical properties of wood is constantly evolving (Beall, 2007; Brashaw et al., 2009). These tools are intended for stakeholders involved in the value creation chain of forest products (Bucur, 2006) where a better understanding of wood properties prior to conversion from one product form to another would better meet customer requirements. Among these non-destructive evaluation technologies are tools that measure the speed of propagation of stress waves, which is positively correlated with the stiffness of wood (Grabianowski et al., 2006). The Director ST300 ${ }^{\mathrm{m}}$ (Fibre-gen, Christchurch, New Zealand), which is designed to perform a stress wave velocity measurement directly on a standing tree (Auty, 2008), is one such tool. This information allows forest managers to select the resource based on mechanical properties of the wood that best meet the demand for raw materials for engineered wood production.

Plantation forest managers often make use of breeding programmes that emphasise growth rate, stem form,

\footnotetext{
* Correspondence: glen.murphy@waiariki.ac.nz

${ }^{2}$ Waiariki Institute of Technology, Rotorua, New Zealand

Full list of author information is available at the end of the article
}

adaptability and disease resistance when choosing stock for replanting (Hernandez et al., 1998). In the case of hybrid poplar, trees can be grown large enough to generate saw timber pieces in less than 15 years. However, as shown by Clair et al. (2003) in research on chestnut, rapid growth in some hardwoods can generate an increase in the amount of reaction wood in the stem thereby reducing the economic potential of the resource due to increased shrinking/swelling and distortion of timber in service. Furthermore, previous studies in poplar have shown that the proportion of reaction wood can vary from 7 to $40 \%$ depending on the clone (Badia et al., 2006).

The influence of reaction wood on stress wave velocity directly measured on the standing tree is not well documented. The proportion of reaction wood is associated with environmental conditions experienced by the tree during its development (Badia et al., 2006). In the case of an environment characterised by the presence of strong wind, the tree will develop a tendency to produce reaction wood to change its centre of gravity so as to bring the stem to a vertical position (forming a curve). This change in the structure of the tree leads to an adjustment of the properties of wood at the section affected by this change, with reaction wood having mechanical properties that

\section{实 Springer}


differ from "normal" wood. It was hypothesised that this change in the structure of the wood will have a measurable influence on stress wave velocity. In addition, we also hypothesise that the curvature of the stem may be a significant morphological criterion for detecting the presence of reaction wood, measurable with a tool such as the ST300. This information could be useful to optimise the standing tree measurement procedure or when acoustic tools are installed on harvesters for sorting logs based on stiffness.

Therefore, the objective of this study was to determine the impact of the presence of reaction wood on the velocity of the stress waves by: (1) comparing the stress wave velocity measurements made parallel to the curvature (convex side of the curve) of the stem and the other one perpendicular to the curvature, i.e. at 90 degrees to the first measurement; (2) determining whether stress wave velocity depends on the severity of the curvature by taking measurements on trees with high and low degrees of curvature and analysing these data using linear regression. The first series of measurements allowed us to determine if the position where acoustic tools are used on the tree will influence the resulting measurements, while the analyses in the second phase allowed us to evaluate the influence of the amplitude of curvature on the stress wave velocity.

\section{Methods}

\section{Experimental design}

The study was carried out in a plantation of two poplar hybrids (Populus deltoides $\times$ nigra and Populus trichocarpa $\times$ deltoides) belonging to GreenWood Resources, Inc. The plantation is situated south of the Columbia River a few kilometres from the city of Boardman in eastern Oregon, USA $\left(45.77^{\circ} \mathrm{N}, 119.54^{\circ} \mathrm{W}\right)$. Plots were located within 8 - or 13-year-old forest blocks with a stand density of approximately 750 stems ha ${ }^{-1}$. The criteria for the location of the plots in the stands took into account the variability of the curvature of the trees so as to have some plots with predominantly straight stems and some plots with stems with very pronounced curvatures.

A total of 15 plots were located in the plantation with four of these selected based on the severity of the curvature of the trees; two had more pronounced curvature than average and, two had less pronounced curvature. The remaining eleven plots were randomly located. The plots were circular with an $8 \mathrm{~m}$ radius, yielding between 13 and 16 trees per plot.

In each plot, a hemispherical laser scan was made using a Faro Focus 3D (Faro Technologies Inc. Lake Mary, Florida, USA). The scanner resolution was set such that a $6.1 \mathrm{~mm}$ gap would be obtained between points hitting an object at a range of $10 \mathrm{~m}$ from the scanner. Particular attention was paid to the positioning of the scanner in order to avoid a plot tree being hidden behind another and not being measured by the scanner. The stress wave velocity of every tree in each of the 15 plots was measured using the ST300 tool (Fibre-gen Ltd., Christchurch, New Zealand). Stress wave velocity was measured at breast height (1.3 $\mathrm{m}$ above the ground) and parallel to the maximum curvature (convex side, see Figure 1). The diameter at breast height (DBH) was also measured. The curvature of the stem was mainly located below or directly at breast height. A second measurement was made at breast height perpendicular to the angle of curvature, i.e. at 90 degrees relative to the first measurement. A flag was installed on the first tree that was located to the east of north of the plot. Acoustic measurements were then gathered systematically on each tree within the plot in a clockwise direction. The flagging of the first tree and clockwise measurement procedure facilitated accurate linking of the scanner data and the individual tree velocity measurements.

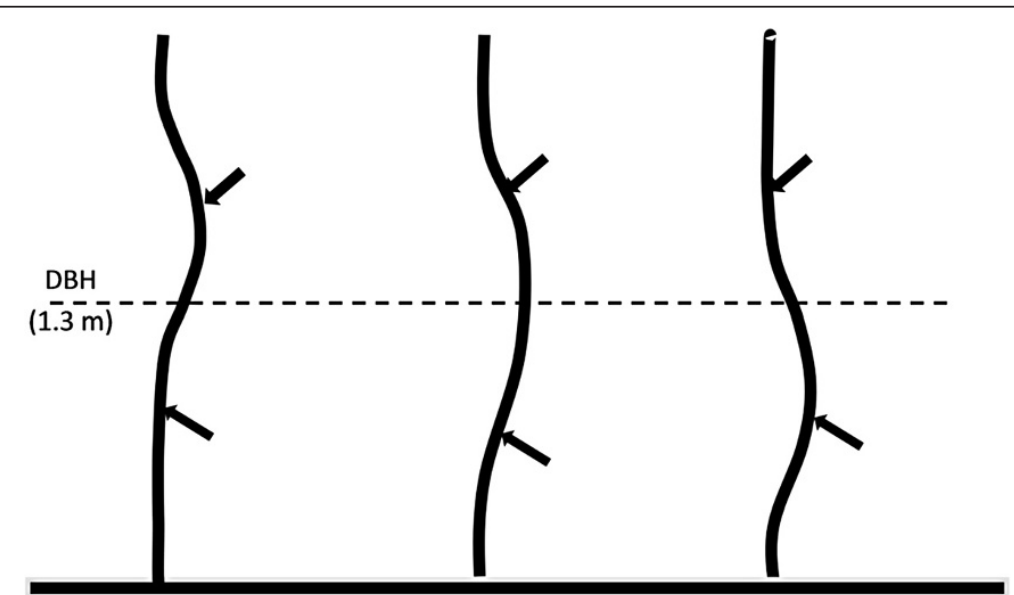

Figure 1 Location of acoustic sensors (black arrows) based on various forms of curvature (measured at DBH). 
The speed with which the mechanical wave travels depends on the type of wave generated, the properties of wood in the direction of wave propagation and the diameter of the tree (Wang et al., Wan 2007). The depth of the probes has an influence on the propagation time since the deeper the probe the shorter time taken by the transmitted wave to reach wood with a lower moisture content (heartwood), so allowing a faster propagation of mechanical waves. Therefore, insertion depth of the probes was kept constant at $3 \mathrm{~cm}$ to minimise the influence of this parameter. During the measurement, the probes were separated by a distance of $50 \pm 5 \mathrm{~cm}$.

The ST300 was tested using a standard brass bar and calibration procedure prior to use in the field. The velocities obtained during the calibration procedure (3.95 to $4.10 \mathrm{~km} \mathrm{~s}^{-1}$ ) were always higher than the value specified in the calibration manual $\left(3.75 \mathrm{~km} \mathrm{~s}^{-1}\right)$, meaning that the device used provided overestimates of velocity compared with a factory calibrated instrument. The error is a fixed difference in the time of flight which would result in a 6 to $13 \%$ overestimate of velocity; larger percentage differences being associated with larger true velocities. Velocities should not, therefore, be directly compared with values from other studies.

\section{Data processing}

The data collected by the scanner were pre-processed using "Autostem" software (Treemetrics Ltd., Cork, Ireland) to obtain three dimensional stem profiles in an appropriate form for making a more thorough analysis of the curvature of the tree. The information generated by "Autostem" does not give the maximum value of the curvature but rather specifies the distance between a vertical axis and the centreline of the tree. Since the data collected by the scanner is very accurate (in the order of a millimetre), it is possible to measure the centreline, and therefore, the curvature of a tree regardless of the orientation of the curve relative to the scanner.

The stem profiles from "Autostem" were then processed using "Sweep Extractor", a program written specifically for this task, to obtain the maximum curvature of a log according to a predetermined length and a predetermined position in the tree. Curvature can be expressed in a number of ways, including the maximum deflection from a straight-line joining the centre points of the two ends of the log. The calculation of the maximum deflection of a $\log$ often requires the rotation of the $\mathrm{x}$ and $\mathrm{y}$ coordinates when the vertical axis is $\mathrm{z}$ (Figure 2).

"Sweep Extractor" generated the data necessary to conduct a detailed study on the relationship between the curvature of the tree and the acoustic velocity. The analysis was applied to two lengths of logs; one extending $3.0 \mathrm{~m}$ above the stump (10 $\mathrm{cm}$ from the ground) and the other extending $6.0 \mathrm{~m}$ from the stump.

\section{Statistical analysis}

Analyses were conducted to compare the stress wave velocities measured using the ST300 at different positions on the tree. The Tukey Honestly Significant Difference test available in the $\mathrm{R}$ package ( $\mathrm{R}$ Development Core Team 2009) was used for all comparison tests. The velocities measured parallel to the curvature (from the convex face) were compared with those measured at 90 degrees to the first measurement. A test for normality of the distribution of the data was performed for this analysis with the Shapiro-Wilk test for normality. The test confirmed that the data were normally distributed $(\mathrm{w}=0.9927$ and $\mathrm{p}=0.2427$ ). It is noted, however, that samples whose speed exceeded $7.5 \mathrm{~km} \mathrm{~s}^{-1}$ were excluded because the ST300 was very sensitive to temperature, tending to overestimate the speed when the outside air temperature

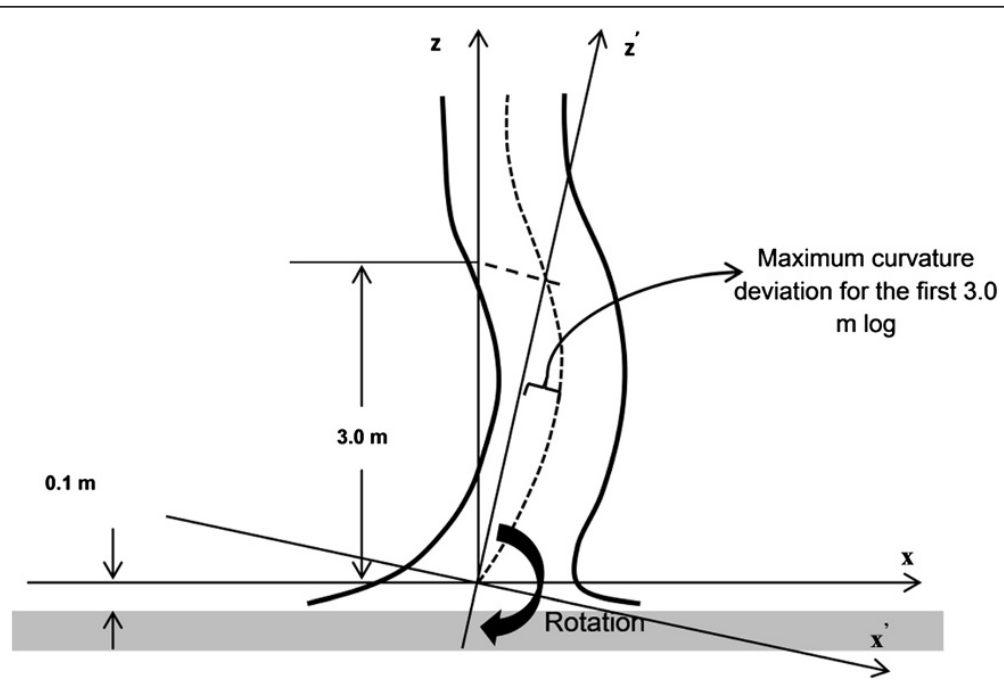

Figure 2 Rotation of axes to determine the maximum curvature deviation for the log. 
Table 1 Characteristics related to 146 samples selected for the study

\begin{tabular}{lcccc}
\hline Variable & \multicolumn{4}{c}{ Characteristic } \\
\cline { 2 - 5 } & Mean & SD & Min & Max \\
\hline DBH $(\mathrm{mm})$ & 260 & 39 & 140 & 339 \\
Dev1 $(\mathrm{mm})$ & 75 & 26 & 6 & 179 \\
Dev2 $(\mathrm{mm})$ & 96 & 37 & 35 & 344 \\
Velocity $\|\left(\mathrm{km} \mathrm{s}^{-1}\right)$ & 6.03 & 0.85 & 3.60 & 8.45 \\
Velocity $\perp\left(\mathrm{km} \mathrm{s}^{-1}\right)$ & 5.93 & 0.82 & 3.74 & 8.12 \\
\hline
\end{tabular}

Dev1 corresponds to the maximum curvature for a first log of $3.0 \mathrm{~m}$. Dev2 is the maximum curve for a first log of $6.0 \mathrm{~m}$ length.

was less than $10^{\circ} \mathrm{C}$. This resulted in a reduction in the number of sample trees from 146 to 128 .

A comparison was also made between the velocities obtained from the 50 samples having the smallest curvatures and the velocities obtained from the 50 samples having the largest curvatures. For this analysis the average of the two velocities measured on the tree (parallel and perpendicular to the curvature) were used. The data were shown to be normally distributed for both the $3 \mathrm{~m} \mathrm{log}$ length $(\mathrm{w}=0.988$ and $\mathrm{p}=0.50)$ and the $6 \mathrm{~m}$ log length $(\mathrm{w}=0.991$ and $\mathrm{p}=0.74)$. The threshold curvatures for the $3 \mathrm{~m}$ log lengths were $<63 \mathrm{~mm}$ and $>84 \mathrm{~mm}$. The thresholds for the $6 \mathrm{~m}$ log length curvatures were $<79$ and $>107 \mathrm{~mm}$.

A linear regression analysis was applied to the results for the two log lengths. Acoustic velocity was considered to be the independent variable, and curvature and DBH were considered to be the dependent variables. For these two regressions, the averages of the two velocities measured on the tree (parallel and perpendicular to the curvature) were used since no significant difference was found between them.

\section{Results and discussion}

Stem size, log curvature, and acoustic velocity measurements (parallel and perpendicular to stem curvature) for the 146 stems selected for the study are summarised in Table 1.

The results of the first comparison analysis show that there is no significant difference $(\mathrm{p}=0.24)$ between measurements taken parallel (convex side) and at 90 degrees to the curvature of the tree. This result is consistent with the behaviour of the mechanical wave generated in this way. The wave front generated reflects all the characteristics associated with wood properties for the entire section of the stem where the measure is taken (Wang et al., 2007; Zhang et al., 2011).

A significant difference at $\mathrm{p}<0.05$ (Table 2) was obtained between the velocities taken on the 50 logs of $3 \mathrm{~m}$ length with smallest curvature with those 50 logs with largest curvature. This result indicates that the curvature of the tree has an effect on the propagation velocity of waves. The results were similar for the $6 \mathrm{~m}$ long logs. Being straight does not necessarily mean that there is no reaction wood since there is always a certain amount of reaction wood in a tree (Jourez et al., 2001; Perre et al., 2012). However, the significant difference in velocities found in this study suggests that there is a greater amount of tension wood in stems having a more pronounced curvature than in stems having a more linear shape. These results are consistent with those observed by Badia et al. (2006) who found that, of three observed stem shapes (straight, leaning and flexuous), the highest percentage of reaction wood was located in the flexuous stems. Badia et al. (2006) also reported that reaction wood was found in greatest concentration in the crown and at the bottom of the tree (the first $50 \mathrm{~cm}$ above the ground). These results are also in agreement with those of Coutland et al. (2004) who reported that poplar reaction wood had higher stiffness than normal wood in both green and dry states. These results differ, however, from those of Saadat-Nia et al. (2011) who found no difference in acoustic velocities between small dry samples of poplar reaction wood and normal wood.

When linear regression was used to predict the acoustic velocity of the tree, the results showed that there was a very weak relationship, $\mathrm{R}^{2}=0.10$, between velocity and the stem curvature and $\mathrm{DBH}$.

\section{Conclusion}

The results demonstrated that the position of the ST300 probes on a tree with respect to the axis of maximum curvature does not affect the stress wave velocity measurement, since no significant difference was found between the velocity measurements taken parallel (convex side) or at 90 degrees to the curvature of the stem in hybrid poplar. However, a significant difference was observed between stress wave velocity in the wood of a stem whose curvature was small compared with the speed on a stem where the curvature was pronounced; average velocities were lower on stems having a small curvature than on stems having a large curvature, suggesting that the green reaction wood is stiffer than normal wood.

Table 2 Average speed based on the curvature of the $\mathbf{5 0}$ least curved and $\mathbf{5 0}$ most curved stems

\begin{tabular}{|c|c|c|c|c|}
\hline Log length (m) & Curvature category & Curvature threshold (mm) & Mean velocity $\left(\mathrm{km} \mathrm{s}^{-1}\right)$ & $\operatorname{Pr}(>\mathrm{F})$ \\
\hline 3 & Smallest 50 logs & $<=63$ & 5.77 & $0.0013^{* *}$ \\
\hline 3 & Largest 50 logs & $>=84$ & 6.28 & \\
\hline 6 & Smallest 50 logs & $<=79$ & 5.80 & $0.012^{*}$ \\
\hline 6 & Largest 50 logs & $>=107$ & 6.20 & \\
\hline
\end{tabular}




\section{Competing interests}

The authors declare that they have no competing interests.

\section{Authors' contributions}

NP carried out the field work and preliminary analyses. Both NP and GM contributed to the writing of the paper. Both authors read and approved the final manuscript.

\section{Acknowledgements}

The authors wish to thank Bruce Summers from GreenWood Resources Inc. for logistical support (transport and on-site accommodation) during fieldwork. Thanks to Jennifer Barnett for assistance with scanner measurements. This research was made possible with contributions from the ForValueNet network (Canada) and from the Stewart Professorship in Forest Engineering, Oregon State University (USA)

\section{Author details}

'Département des Sciences du Bois et de la Forêt, Université Laval, Québec, Canada. ${ }^{2}$ Waiariki Institute of Technology, Rotorua, New Zealand.

Received: 16 July 2013 Accepted: 16 July 2013

Published: 08 Aug 2013

\section{References}

Auty, D, \& Achim, A. (2008). The relationship between standing tree acoustic assessment and timber quality in Scots pine and the pratical implications for assessing timber quality from naturally regenerated stands. Forestry, 81(4), 475-487.

Badia, MA, Constant, T, Mothe, F, \& Nepveu, G. (2006). Tension wood occurrence in three cultivars of Populus $x$ euramericana. Part I: Inter-clonal and intra-tree variability of tension wood. Annals of Forest Science, 63, 23-30.

Beall, FC. (2007). Industrial applications and opportunities for nondestructive evaluation of structural wood members. Maderas. Ciencia y tecnología, 9, 127-134.

Brashaw, BK, Bucur, V, Divos, F, Gonçalves, R, Lu, J, Meder, R, et al. (2009). Nondestructive testing and evaluation of wood: a worldwide research update. Forest Products Journal, 59(3), 7-14.

Bucur, V. (2006). Acoustics of wood. (pp. 220-226) Springer-Verlag, Berlin Heidelberg.

Clair, B, Ruelle, J, \& Thibaut, B. (2003). Relationship between growth stresses, mechano-physical properties and proportion of fibre with gelatinous layer in chestnut (Castanea Sativa Mill.). Holzforschung, 57, 189-195.

Coutland, C, Jeronomidis, G, Chanson, B, \& Loup, C. (2004). Comparison of mechanical properties of tension wood and opposite wood in Populus spp. Wood Science and Technology, 38(1), 11-24.

Grabianowski, M, Manley, B, \& Walker, JCF. (2006). Acoustic measurements on standing trees, logs and green lumber. Wood Science and Technology, 40(3), 205-216.

Hernandez, R, Koubaa, A, Beaudoin, M, \& Fortin, Y. (1998). Selected mechanical properties of fast-growing poplar hybrid clones. Wood and Fiber Science, 30, 138-147.

Jourez, B, Riboux, A, \& Leclercq, A. (2001). Anatomical characteristics of tension wood and opposite wood in young inclined stems of poplar (Populus euramericana cv "ghoy"). IAWA Journal, 22, 133-157.

Perre, P, Dinh, AT, Assor, C, Frank, X, \& Pilate, G. (2013). Stiffness of normal, opposite, and tension poplar wood determined using micro-samples in the three material directions. Wood Science and Technology, 47(3), 481-498.

Saadat-Nia, MA, Brancheriau, L, Gallet, P, Enayati, AA, Pourtahmasi, K, \& Honarvar, F. (2011). Ultrasonic wave parameter changes during propagation through poplar and spruce reaction wood. Bioresources, 6(2), 1172-1185.

Wang, X, Ross, RJ, \& Carter, P. (2007). Acoustic evaluation of wood quality in standing trees. Part I. Acoustic wave behavior. Wood and Fiber Science, $39(1), 28-38$

Zhang, H, Wang, X, \& Su, J. (2011). Experimental investigation of stress wave propagation in standing trees. Holzforschung, 65, 743-748.

\subsection{6/1179-5395-43-7}

Cite this article as: Paradis and Murphy: Effects of curvature in hybrid poplar on acoustic velocity at the tree level. New Zealand Journal of Forestry Science 2013, 43:7

\section{Submit your manuscript to a SpringerOpen ${ }^{\circ}$ journal and benefit from:}

- Convenient online submission

- Rigorous peer review

- Immediate publication on acceptance

- Open access: articles freely available online

- High visibility within the field

- Retaining the copyright to your article

Submit your next manuscript at $>$ springeropen.com 